\title{
Helix N-Cap Residues Drive the Acid Unfolding That Is Essential in the Action of the Toxin Colicin A
}

Yan Huang, ${ }^{\dagger, \ddagger}$ Andrei Soliakov, ${ }^{\dagger}$ Anton P. Le Brun, ${ }^{\dagger, \S}$ Colin Macdonald, ${ }^{\|}$Christopher L. Johnson, ${ }^{\dagger}$ Alexandra S. Solovyova, ${ }^{\dagger}$ Helen Waller, ${ }^{\dagger}$ Geoffrey R. Moore, ${ }^{\|}$and Jeremy H. Lakey ${ }^{*}{ }^{\dagger}(0)$

${ }^{\dagger}$ Institute for Cell and Molecular Biosciences, The Medical School, Newcastle University, Framlington Place, Newcastle-upon-Tyne NE2 4HH, U.K.

"College of Chemistry and Molecular Sciences, Wuhan University, Wuhan 430072, People’s Republic of China

${ }^{\S}$ Australian Centre for Neutron Scattering, Australian Nuclear Science and Technology Organisation, Kirrawee DC, NSW 2232, Australia

"Department of Chemistry Centre for Structural \& Molecular Biology, School of Chemistry, University of East Anglia, Norwich Research Park, Norwich NR4 7TJ, U.K.

\section{Supporting Information}

ABSTRACT: Numerous bacterial toxins and other virulence factors use low $\mathrm{pH}$ as a trigger to convert from water-soluble to membrane-inserted states. In the case of colicins, the pore-forming domain of colicin A (ColA-P) has been shown both to undergo a clear acidic unfolding transition and to require acidic lipids in the cytoplasmic membrane, whereas its close homologue colicin $\mathrm{N}$ shows neither behavior. Compared to that of ColN-P, the ColA-P primary structure reveals the replacement of several uncharged residues with aspartyl residues, which upon replacement with alanine induce an unfolded state at neutral $\mathrm{pH}$. Here we investigate ColA-P's structural requirement for these critical aspartyl residues that are largely situated at the $\mathrm{N}$-termini of $\alpha$ helices. As previously shown in model peptides, the charged carboxylate side chain can act as a stabilizing helix $\mathrm{N}$-Cap group by interacting with free amide hydrogen bond donors. Because this could explain ColA-P destabilization when the aspartyl residues are protonated

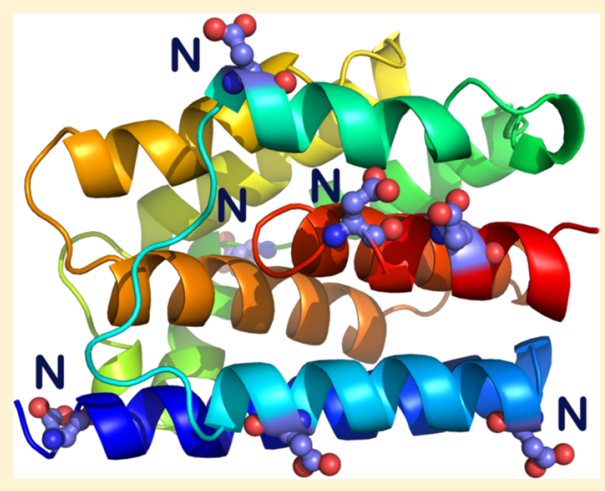
or replaced with alanyl residues, we test the hypothesis by inserting asparagine, glutamine, and glutamate residues at these sites. We combine urea (fluorescence and circular dichroism) and thermal (circular dichroism and differential scanning calorimetry) denaturation experiments with ${ }^{1} \mathrm{H}-{ }^{15} \mathrm{~N}$ heteronuclear single-quantum coherence nuclear magnetic resonance spectroscopy of ColA-P at different $\mathrm{pH}$ values to provide a comprehensive description of the unfolding process and confirm the N-Cap hypothesis. Furthermore, we reveal that, in urea, the single domain ColA-P unfolds in two steps; low $\mathrm{pH}$ destabilizes the first step and stabilizes the second.

$\mathrm{L}$ ow-pH-induced conformational change is a feature of many infectious processes. Some involve pore-forming toxins such as anthrax ${ }^{1}$ and diphtheria, ${ }^{2-4}$ but influenza infection is also $\mathrm{pH}$-dependent due to the need for the hemagglutinin protein to undergo low- $\mathrm{pH}$-induced conformational change. ${ }^{5,6}$ Both hemagglutinin and protein toxins must remain as water-soluble proteins until required to enter the membrane, and the low $\mathrm{pH}$ of the late endosome supplies the specific trigger for activation. This is also true for neurotoxins that translocate across the endosomal membrane. ${ }^{7,8}$ Interactions with lipid rafts also regulate toxin insertion, ${ }^{9}$ and in bacteria, there is evidence that localization of acidic lipids may fine-tune membrane-bound protein function. ${ }^{10}$ The Escherichia coli pore-forming type III secretion-system protein, EspD, is activated by both low $\mathrm{pH}$ and acidic lipids. ${ }^{11}$

Colicins are bacterial protein toxins that kill Gram-negative bacteria such as E. coli by translocating across the outer membrane to deliver a toxic C-terminal domain, with pore forming or nuclease activity, into the cytoplasmic membrane. ${ }^{12,13}$ In pore-forming colicins, these domains enter the energized inner membrane and depolarize it by ion release. ${ }^{14}$ The water-soluble pore-forming domains of colicins are conserved 10-helix bundles, similar to Bcl2-family apoptosis regulators, ${ }^{15}$ which contain a buried hydrophobic helical hairpin that is important in membrane insertion and channel formation. These domains are stable folded proteins so their tertiary structure needs to be destabilized to enable the unfolding that must precede membrane insertion. ${ }^{16}$

Several colicins insert into membranes more rapidly at very low $\mathrm{pH},{ }^{12}$ but importantly, only one, colicin $\mathrm{A}$, shows a clear $\mathrm{pH}$-dependent change in stability that has a demonstrated biological relevance. The colicin A P-domain unfolds with a

Received: August 12, 2019

Revised: October 31, 2019

Published: November 5, 2019 


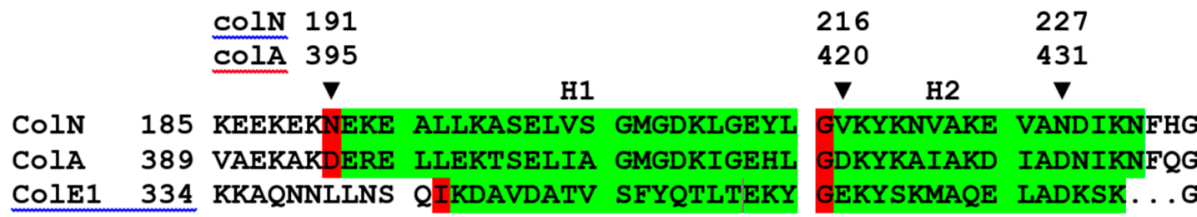

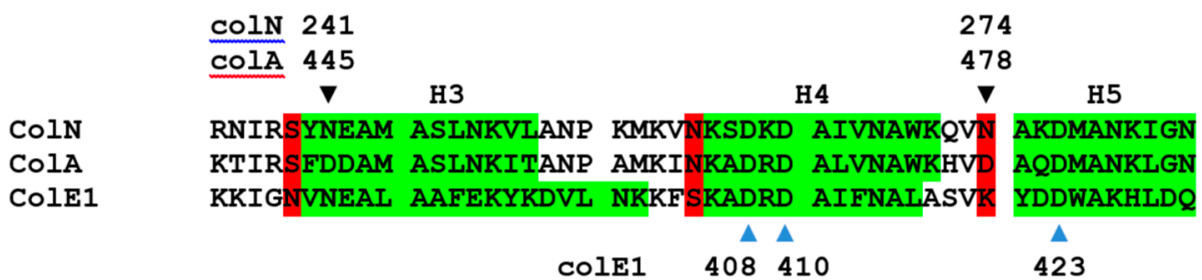

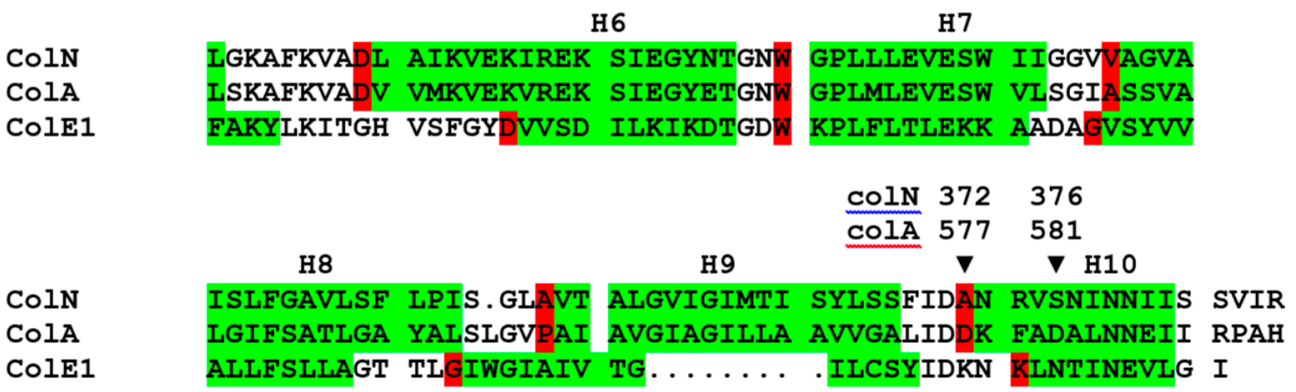

Figure 1. Sequence alignment of colicin pore-forming domains. C-Terminal pore-forming domains of colicin N (UniProtKB P08083), colicin A (UniProtKB P04480), and colicin E1 (UniProtKB P02978) are shown. Helices are colored green, and N-Cap positions red. Residues mutated in this study are shown by black triangles $(\boldsymbol{\nabla})$ with numbering for full length colicin A and N. Residues thought to be involved in acid destabilization of colicin E1 are shown with blue triangles.

clear transition at $\mathrm{pH} 3.5$ that is directly correlated with the rate of membrane insertion. ${ }^{16}$ The presence of acidic lipids in the model membrane reduces the interfacial $\mathrm{pH}$ and allows molten globule formation at a higher bulk $\mathrm{pH}$. Crucially, this behavior is relevant in vivo because colicin $\mathrm{A}$ is dependent upon acidic lipids in the E. coli cytoplasmic membrane whereas the closely related but $\mathrm{pH}$ insensitive colicin $\mathrm{N}$ is not. ${ }^{17}$ This shows that the observed $\mathrm{pH}$-dependent stability of colicin $\mathrm{A}$ is relevant to an essential event that takes place at the cytoplasmic membrane in vivo. The colicin $\mathrm{B}$ pore-forming domain (ColB-P) which is highly homologous to ColA-P ${ }^{18}$ shows similar in vitro behavior, ${ }^{19,20}$ but its in vivo dependence upon acidic lipids is not known.

The pore-forming domain of colicin E1 (ColE1-P), which has also been intensively investigated, inserts into model membranes more rapidly below $\mathrm{pH} 4.0^{21,22}$ but unlike colicins $\mathrm{A}$ and $\mathrm{B}$ only partly unfolds at low $\mathrm{pH}$ and retains a significant near-ultraviolet (near-UV) CD signal even at $\mathrm{pH} 2.0 .^{23}$

In addition to strong sequence homology (Figure 1), the high-resolution structures of colicins A [Protein Data Bank (PDB) entry $1 \mathrm{COL}],{ }^{24} \mathrm{~B}$ (PDB entry $\left.1 \mathrm{RH} 1\right),{ }^{18}$ and $\mathrm{N}$ (PDB entry $1 \mathrm{~A} 87)^{25}$ show a backbone root-mean-square structural deviation (RMSD) of $<3 \AA$ for their pore-forming domains (Figure S1). However, ColA-P and ColB-P have isoelectric points (pI) (4.5 and 4.25, respectively) that are much lower than that of ColN-P $(\mathrm{pI}=10.4),{ }^{20}$ due to the presence of aspartic acid residues in ColA-P and ColB-P at sites where neutral residues are found in ColN. In a previous study, single aspartate residues conserved in ColA-P and ColB-P but not ColN-P were changed to uncharged alanines. Surprisingly, seven of eight of these single Asp to Ala mutants showed a partial molten globule phenotype at neutral $\mathrm{pH}$, implying that removal of the negative charges by Ala mutation or at low $\mathrm{pH}$ was responsible for ColA-P instability. ${ }^{26}$ Furthermore, this could be directly linked to function because aspartate to alanine mutation increases the rate of insertion of ColA-P more into lipid vesicles at neutral $\mathrm{pH}^{26}$ Most models of $\mathrm{pH}$ dependent protein structure invoke folding-dependent changes in the $\mathrm{p} K_{\mathrm{a}}$ of amino acid residue side chains, which is more applicable to buried residues or those in ion pairs or hydrogen bonds. ${ }^{27}$ As a group, the stabilizing colicin A aspartates do not all fit into any one of these categories, so how they show similar $\mathrm{pH}$-dependent effects was unclear.

In this study, we propose a mechanism that explains the $\mathrm{pH}$ sensitivity of ColA-P and is potentially applicable to other proteins. We initially show that urea denaturation causes a twostage unfolding of ColA-P and that both stages are $\mathrm{pH}$ dependent. The first transition, which forms the molten globule, occurred at lower urea concentrations as the $\mathrm{pH}$ was decreased, while the second transition moved to higher urea concentrations. We then showed that the first transition is highly sensitive to substitution of the critical aspartate residues with alanine but not when they are replaced with asparagine. This behavior fits with work by Doig and Baldwin who showed that isolated $\alpha$ helices can be stabilized if the non-hydrogenbonded backbone amide groups at their $\mathrm{N}$-termini are capped by a suitable residue, with the most stabilizing being Asn $>$ $\mathrm{Asp}^{-}>\mathrm{Cys}^{-}>\mathrm{Trp}>\mathrm{Gly}>\mathrm{Ser}^{28}{ }^{28}$ We then performed ${ }^{1} \mathrm{H}-{ }^{15} \mathrm{~N}$ heteronuclear single-quantum coherence (HSQC) nuclear magnetic resonance (NMR) experiments and showed that single alanine point substitutions of these capping aspartates have widespread effects on the dynamics of the Col-AP domain. The role of $\mathrm{N}$-Cap residues suggests a mechanism for $\mathrm{pH}$ sensitivity whereby destabilization of the ends of $\alpha$ helices is sufficient to induce the molten globule state, which is required for colicin A to insert into membranes. Inspection of 
other $\mathrm{pH}$-dependent proteins reveals that such caps could be important triggers elsewhere in biology where $\mathrm{pH}$-dependent conformational change has been observed. ${ }^{29,30}$ The recent demonstrations of acidic lipid localization in bacteria make the requirement by colicin A for acidic lipids of renewed interest, and these molecules may be useful probes of lipid distribution in bacteria ${ }^{10,31-33}$

\section{METHODS}

All chemicals were either from Sigma-Aldrich (Poole, Dorset, U.K.) or from Melford Laboratories Ltd. unless otherwise stated. For molecular biology, genes were synthesized and cloned into plasmid pET3c by Blue Heron Biotechnology. NiNTA resin was purchased from Qiagen. The Wizard Plus SV Miniprep DNA purification system was purchased from Promega.

The bacterial strains used throughout the project were Epicurian coli XL1-Blue supercompetent cells, used to amplify plasmids for purification and Escherichia coli BL21(DE3) and E. coli BL21-AI Thermo Fisher used to produce colicin A poreforming domain (UniProtKB Q47108) proteins with an Nterminal HHHHHHSS tag. ${ }^{26}$ ColA-P wild type, D395A, D420A, D431A, and D577A were purified from E. coli BL21(DE3), while we used E. coli BL21-AI for D445A and D582A to obtain better yields.

After ColA plasmids had been transformed into BL21 cells, one single colony was picked from an ampicillin L-agar plate and inoculated into $50 \mathrm{~mL}$ of $\mathrm{LB}$ medium (with $100 \mu \mathrm{g} / \mathrm{mL}$ ampicillin) and incubated at $37{ }^{\circ} \mathrm{C}$ overnight in an orbital incubator, shaking at $180 \mathrm{rpm}$. Then, $4 \times 500 \mathrm{~mL}$ of $\mathrm{LB}$ (containing $100 \mu \mathrm{g} / \mathrm{mL}$ ampicillin) in $2 \mathrm{~L}$ shake flasks were inoculated with $5 \mathrm{~mL}$ of overnight culture and grown at $37^{\circ} \mathrm{C}$ while being shaken until the $\mathrm{OD}_{600}$ reached $0.8-1.0$. The expression of protein was induced by $0.2 \%$ arabinose BL21-AI or $1 \mathrm{mM}$ isopropyl $\beta$-D-thiogalactopyranoside (ITPG) in BL21(DE3). The cell culture was grown for a further $3 \mathrm{~h}$ until the $\mathrm{OD}_{600}$ reached $1.8-2.0$. ${ }^{15} \mathrm{~N}$-labeled proteins were expressed using M9 medium supplemented with $\left[{ }^{15} \mathrm{~N}\right]$ ammonium chloride. Before the large-scale culture had been set up, the cells from the preculture were pelleted and resuspended in M9 medium. The cells were pelleted by centrifugation using a Beckman Avanti series centrifuge JA-10 rotor at $10000 \mathrm{~g}$ for $10 \mathrm{~min}$ at $4{ }^{\circ} \mathrm{C}$. All colicin constructs were purified as described previously, ${ }^{26}$ followed by dialysis into 50 $\mathrm{mm}$ sodium phosphate $(\mathrm{pH} 7.6)$ and $300 \mathrm{mM} \mathrm{NaCl}$.

Circular dichroism was measured using a J-810 spectropolarimeter (Jasco) and Quartz-Suprasil cuvettes (Hellma, $\mathrm{GmbH} \& \mathrm{Co}$.). The far-UV spectrum was averaged over 10 accumulations in a $0.2 \mathrm{~mm}$ cuvette at $0.5 \mathrm{mg} / \mathrm{mL}$ between 190 and $260 \mathrm{~nm}$, and the near-UV spectrum in a $5 \mathrm{~mm}$ cuvette at $2.0 \mathrm{mg} / \mathrm{mL}$ between 250 and $320 \mathrm{~nm}$. The buffer spectrum was subtracted from the sample spectrum before conversion into standard units of $\Delta \varepsilon\left(\mathrm{M}^{-1} \mathrm{~cm}^{-1}\right)$. Thermal unfolding was measured using a $1{ }^{\circ} \mathrm{C} \mathrm{min}^{-1}$ ramp between 20 and $90{ }^{\circ} \mathrm{C}$ using a wavelength of $223 \mathrm{~nm}$ for secondary structure and 295 nm for tertiary structure.

Tryptophan fluorescence emission spectra were measured with a Cary Eclipse spectrofluorometer (Varian) using a 280 $\mathrm{nm}$ excitation wavelength. Slits were set to provide bandwidths of $5 \mathrm{~nm}$ for both excitation and emission. Emission spectra were recorded between 300 and $450 \mathrm{~nm}$ with a scan rate of $600 \mathrm{~nm} / \mathrm{min}$ in a $0.5 \mathrm{~cm}$ path length cuvette at $25^{\circ} \mathrm{C}$. For each condition, three spectra were averaged. Fluorescence spectra of
ColA-P mutants and wild type were measured over a urea solution concentration range from 0 to $9.1 \mathrm{M}$ and a guanidine solution concentration range from 0 to $7.8 \mathrm{M}$. Samples were equilibrated for at least $8 \mathrm{~h}$ before measurement; $50 \mathrm{mM}$ phosphate buffer was used between $\mathrm{pH} 8.0$ and 6.0, and 50 $\mathrm{mM}$ sodium citrate buffer at $\mathrm{pH} \leq 5.0$. The barycentric means of the emission wavelength were calculated as previously described. ${ }^{34}$ This involves calculating the center of mass of the spectrum plotted as intensity versus wavelength and thus measures wavelength shifts using the maximum amount of data available. It has been shown to accurately measure shifts in the single-nanometer range ${ }^{35}$ and is calculated using the following relationship:

$$
\mathrm{BCM}=\frac{\sum\left(F_{\lambda} \lambda\right)}{\sum\left(F_{\lambda}\right)}
$$

where $\mathrm{BCM}$ is the barycentric mean and $F_{\lambda}$ is fluorescence intensity at wavelength $\lambda$. In these experiments, the wavelength range was 295-440 nm. Thermal denaturation of ColA-P and mutants was studied by differential scanning calorimetry (DSC). The protein samples were studied in a temperature range of $25-90{ }^{\circ} \mathrm{C}$ at a scanning rate of $1{ }^{\circ} \mathrm{C} / \mathrm{min}$. The proteins were dissolved in $50 \mathrm{mM}$ phosphate buffer to a concentration of $0.5 \mathrm{mg} / \mathrm{mL}$, determined by UV absorption in $1 \mathrm{~cm}$ path length cuvettes at $\mathrm{pH} 7.0$ using the measured extinction coefficient $(E)$ of $\sim 2.43 \times 10^{4} \mathrm{M}^{-1} \mathrm{~cm}^{-1}$. ${ }^{36}$ The melting temperature and calorimetric enthalpy were determined.

The ${ }^{1} \mathrm{H}-{ }^{15} \mathrm{~N}$ HSQC spectra of ${ }^{15} \mathrm{~N}$-labeled ColA-P (with a histidine tag) were recorded in $50 \mathrm{mM}$ sodium citrate buffer $(\mathrm{pH} 4.5)$ or $50 \mathrm{mM}$ phosphate buffer $(\mathrm{pH} \mathrm{8.0)}$ and $10 \%(\mathrm{v} / \mathrm{v})$ ${ }^{2} \mathrm{H}_{2} \mathrm{O}$ at $298 \mathrm{~K}$ on a Bruker Avance III spectrometer operating at ${ }^{1} \mathrm{H}$ and ${ }^{15} \mathrm{~N}$ frequencies of 800.229 and $81.09 \mathrm{MHz}$, respectively, processed with Bruker TopSpin 2.1 NMR, and analyzed using the collaborative computing project for NMR (CCPN) analysis. ${ }^{1} \mathrm{H}$ chemical shifts were referenced directly to external 2,2-dimethyl-2-silapentane-5-sulfonate sodium salt DSS, and ${ }^{15} \mathrm{~N}$ chemical shifts indirectly to DSS. ${ }^{37}$

Size exclusion chromatography was carried out using a Superose 12 column from GE Healthcare UK equilibrated with $50 \mathrm{mM}$ sodium phosphate and $150 \mathrm{mM} \mathrm{NaCl}$ ( $\mathrm{pH} 7.4$ ). Sedimentation velocity (SV) experiments were carried out in a Beckman Coulter (Palo Alto, CA) ProteomeLab XL-I analytical ultracentrifuge. All analytical ultracentrifugation (AUC) runs were carried out at a rotation speed of 48000 rpm at $4{ }^{\circ} \mathrm{C}$ using an eight-hole An-Ti50 rotor and doublesector aluminum-Epon centerpieces. The sample volume was $400 \mu \mathrm{L}$, and the concentrations ranged from 0.1 to $0.76 \mathrm{mg} /$ $\mathrm{mL}$. The partial specific volumes for the proteins were calculated from the protein amino acid sequence, using SEDNTERP. ${ }^{62}$ The density and viscosity of the buffer [20 $\mathrm{mM}$ Tris and $150 \mathrm{mM} \mathrm{NaCl}(\mathrm{pH} \mathrm{7.5)}]$ at the experimental temperature were also calculated using SEDNTERP. Sedimentation velocity profiles were treated using the size distribution $c(s)$ model implemented in SEDFIT. ${ }^{32}$ Integrated values of the sedimentation coefficient obtained under experimental conditions were converted to the standard conditions $\left(s_{20, \mathrm{w}}\right)$ (which is the value of the sedimentation coefficient in water at $20{ }^{\circ} \mathrm{C}$ ). The sedimentation coefficient for the monomeric form was calculated on the basis of atomic coordinates (PDB entry $1 \mathrm{COL}$ ) using program SoMo. ${ }^{38} \mathrm{~A}$ plausible symmetrical dimer was generated using PyMOL, 39 

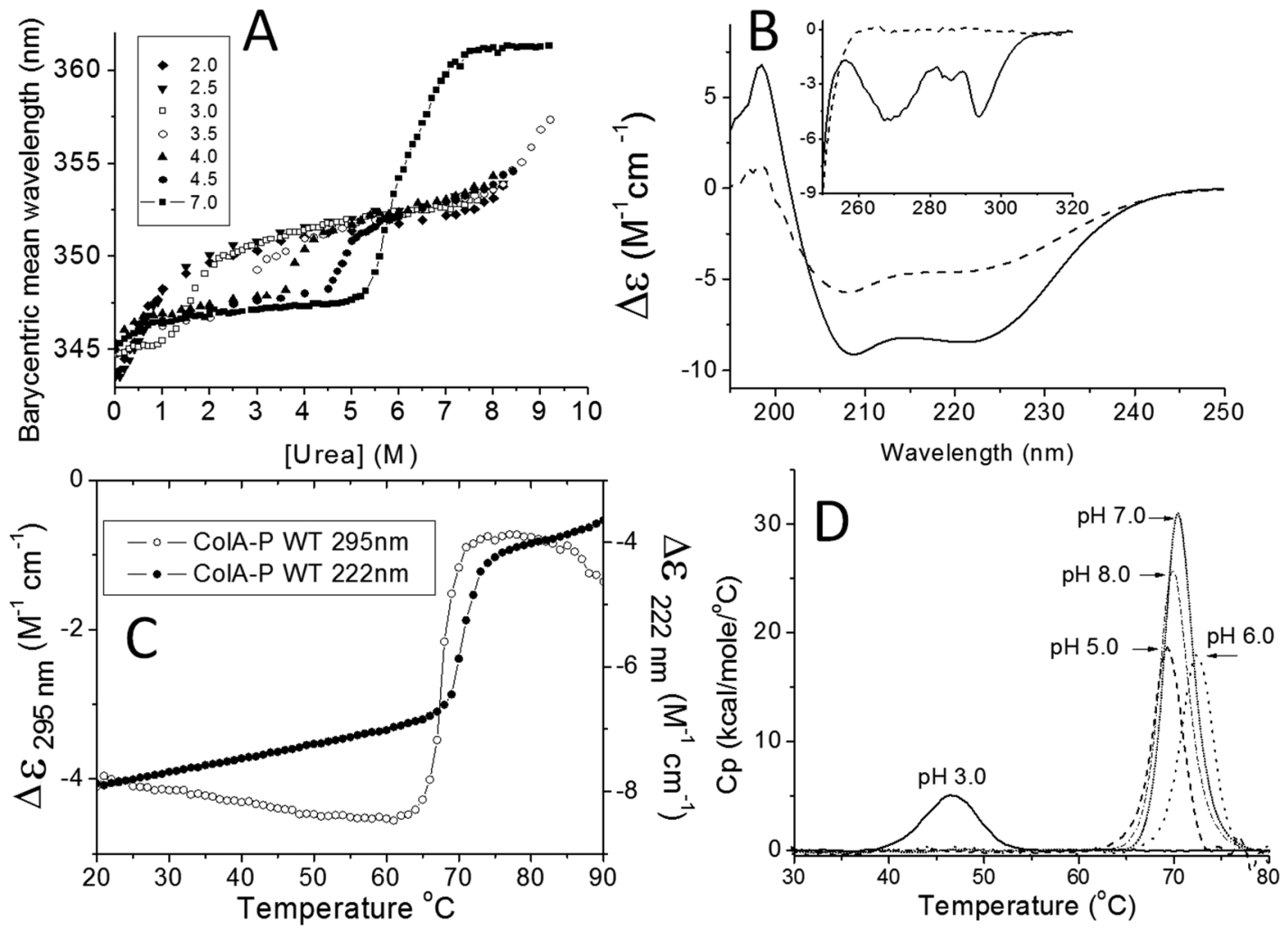

Figure 2. Colicin A P-domain WT unfolding characteristics. (A) Urea-dependent unfolding of ColA-P at acidic $\mathrm{pH}$ measured by the shift of the barycentric mean wavelength (BMW) of the intrinsic tryptophan fluorescence. Samples were equilibrated in $50 \mathrm{mM}$ citrate buffer and urea for $>8 \mathrm{~h}$ before measurement or $50 \mathrm{mM}$ phosphate for $\mathrm{pH}$ 7.0. (B) Effect of temperature on the far-UV and (inset) near-UV CD spectrum of ColA-P at $\mathrm{pH}$ 7.0. Solid line for $25{ }^{\circ} \mathrm{C}$ and dashed line for $80^{\circ} \mathrm{C}$. (C) Thermal transitions for near-UV CD measured at $295 \mathrm{~nm}$ (left ordinate axis) and far-UV $\mathrm{CD}$ measured at $222 \mathrm{~nm}$ (right ordinate axis). (D) DSC scans $\left(1^{\circ} \mathrm{C} / \mathrm{min}\right)$ of ColA-P solutions at different $\mathrm{pH}$ values.

and its sedimentation coefficient was calculated using SoMo as described above.

\section{RESULTS}

The Colicin A P-Domain Shows Biphasic Urea Unfolding. The destabilizing effects of ColA-P Asp to Ala mutations have been noted before, ${ }^{26}$ and here we quantified their stability across a range of $\mathrm{pH}$ values using urea equilibrium denaturation. Unfolding ColA-P shifts its intrinsic tryptophan fluorescence emission to longer wavelengths (Figure 2A), and we used the changes in the barycentric mean emission wavelength ${ }^{34}$ to follow unfolding. At $\mathrm{pH} 7.0$, ColA-P showed what initially appeared to be a single unfolding transition with a midpoint close to $6 \mathrm{M}$ urea; however, upon closer inspection, it was clear that it was formed of two closely adjacent phases.

As the $\mathrm{pH}$ was decreased, both transitions shifted but in opposite directions along the urea concentration axis. The first transition moved toward a lower urea concentration, while the second transition moved to higher concentrations such that, eventually, it did not unfold within the urea concentration range used. At $\mathrm{pH}<3.0$, where molten globule (MG) formation in WT ColA-P is complete, ${ }^{16,40}$ the first unfolding transition was already underway at $0 \mathrm{mM}$ urea. The shift in the second transition to a high urea concentration appears complete at $\mathrm{pH} 4.5$, but because the full transition is not observed within the urea concentration range that is used, it is unclear whether this continues to change at even lower $\mathrm{pH}$ values. ColA-P was also subjected to thermal unfolding monitored by both far-UV $(222 \mathrm{~nm})$ and near-UV $(295 \mathrm{~nm})$
$\mathrm{CD}$ at $\mathrm{pH} 7.0$ (Figure 2B). Significantly, the secondary structure did not fully unfold before the maximum temperature of $95{ }^{\circ} \mathrm{C}$ was reached, whereas the tertiary structure signal was completely lost by $80{ }^{\circ} \mathrm{C}$ (Figure 2C). Measuring these transitions at different $\mathrm{pH}$ values using $\mathrm{DSC}^{19}$ confirmed the previously published data that the protein is most stable at $\mathrm{pH}$ $6-7^{40}$ and that it is significantly destabilized by pH 3.0 (Figure 2D). The monomeric state of ColA-P was confirmed by sedimentation velocity assays using AUC (Figure S2). Size exclusion chromatography indicated the size of ColA-P $\left(M_{\mathrm{W}}=\right.$ 22918.3 Da) to be $21182 \mathrm{Da}$, while AUC sedimentation velocity measured a sedimentation coefficient $\left(s_{20, \mathrm{~W}}\right)$ of 2.189 $\pm 0.005 \mathrm{~S}$ and a molecular weight of the solute $\left(M_{\mathrm{W}}\right)$ of 22680 $\pm 1280 \mathrm{Da}$ with virtually no aggregated material (Figure S2).

Asp to Ala Mutants Show Destabilized Biphasic Unfolding. As previously reported, the replacement of specific aspartyl residues with alanyl residues significantly reduces the stability of ColA-P. ${ }^{26}$ Here we show that the mutants altered the urea unfolding profile mainly by decreasing the urea concentration required to reach the first unfolding transition. This means that, unlike the WT, the mutants show clear biphasic unfolding even at neutral $\mathrm{pH}$ (Figure $3 \mathrm{~A}$ ). To better resolve the second unfolding transition that is incomplete in 8 $\mathrm{M}$ urea, guanidine hydrochloride $(\mathrm{GdnHCl})$ was used instead due to its stronger denaturing effect. Under these conditions, the second transition was completed, as previously seen for $\mathrm{ColB},{ }^{41}$ confirming the previous urea-derived data for ColA-P WT.

The similar results from the two denaturants are informative because charge-charge interactions at the protein surface will 

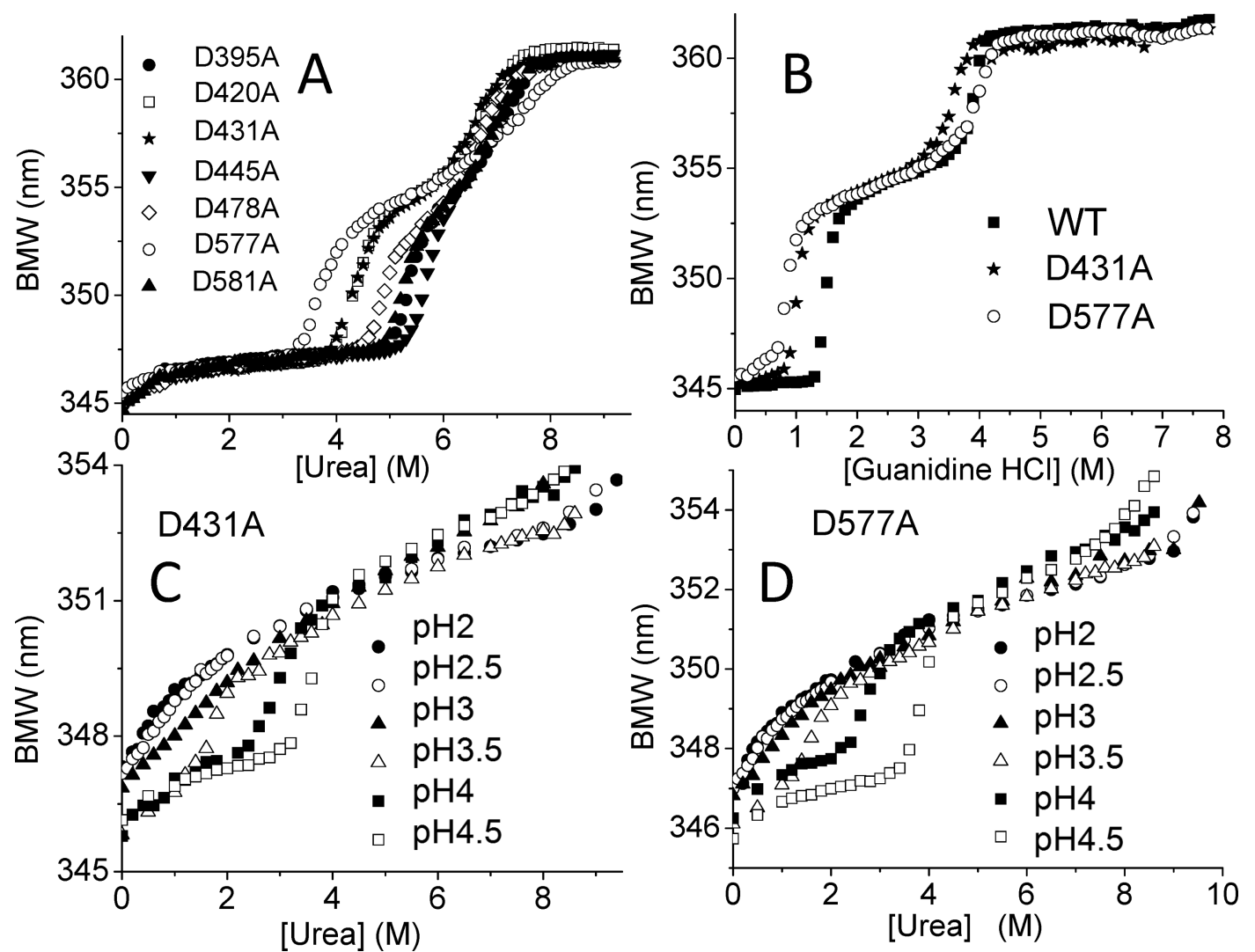

Figure 3. Alanine substitution mutants mainly destabilize the first urea unfolding transition. (A) Urea denaturation of ColA-P Asp to Ala mutants at $\mathrm{pH}$ 7.0. (B) $\mathrm{GdnHCl}$ denaturation of Asp to Ala mutants at $\mathrm{pH}$ 7.0. (C) Urea denaturation of the ColA-P D431A mutant at low pH. (D) Urea denaturation of the ColA-P D577A mutant at low $\mathrm{pH}$. BMW is the barycentric mean wavelength.

be weakened in the high ionic strength of the $\mathrm{GdnHCl}$ solutions used here (Figure 3B). Measurements under acidic conditions showed that the $\mathrm{pH}$ sensitivity of the transitions was retained or even exaggerated by single Asp to Ala substitutions (Figure 3C,D). Thermal unfolding monitored by circular dichroism (CD) in the near- and far-UV ranges showed that the first unfolding transition occurred at reduced temperatures for D431A and D577A while the previously unattained second transition was complete for most mutants below $90{ }^{\circ} \mathrm{C}$ (Figure 4A,B). The broad effects of aspartate removal are thus similar to those caused by low $\mathrm{pH}$ (Figure $2 \mathrm{~A})$. If the unfolding were to occur via a simple two-state transition, urea denaturation could also provide a quantitative estimate of stability by providing a value for the Gibbs free energy of folding $\left(\Delta G_{\text {fold }}\right)$. However, the discovery of biphasic unfolding meant that the midpoint between the two transitions was difficult to define and furthermore the upper transition was often incomplete. Thus, in spite of the detailed urea unfolding data that were obtained, unequivocal determination of the unfolding free energies for the transitions was not possible. Our comparisons are therefore based upon the relative positions of the midpoints of the transitions.

From this, it is clear that the first unfolding transition is particularly sensitive to the removal of several individual Asp residues. However, all single Ala insertion mutants remained sensitive to $\mathrm{pH}$, so multiple sites contribute to acid unfolding.

Thermal Stability of Aspartate to Alanine Mutants Measured by DSC. Wild type and mutant ColA-P were further analyzed by DSC at $\mathrm{pH}$ 7.0. For all of the proteins studied, a single sharp unfolding transition was observed as a peak in the specific heat capacity versus temperature plot with a good post-transition baseline and no evidence of exothermic aggregation. However, scans were not completely reversible; therefore, $\Delta H_{\text {cal }}$ is an estimate, and more detailed analysis is not presented. All of the Asp to Ala mutations showed lower thermal transition temperatures and a reduced $\Delta H_{\text {cal }}$ compared to those of the WT. The reductions in $T_{\mathrm{m}}$ and $\Delta H_{\mathrm{cal}}$ correlate with the decrease in the stability of the initial transition during urea denaturation (Table 1 and Figure 4C).

There is no evidence in the DSC data of the biphasic thermal unfolding observed by fluorescence spectroscopy in mutants such as D431A. The resolved DSC peaks appear to match the $\mathrm{pH}$ and mutation sensitive first urea unfolding transition (Figures 2-4A,B), and thus, we did not detect the second transition by DSC. The sharp DSC transition of ColA$\mathrm{P}$ declines in both temperature and size with a decrease in $\mathrm{pH}$ and largely disappears upon acidic molten globule formation. ${ }^{40}$ This suggests that the single observed DSC peak and the first urea unfolding transition correlate with molten globule formation.

Aspartate to Asparagine Mutations Maintain the Stability of ColA-P. The data show that removal of the Asp negative charge, at specific sites, by protonation or alanine substitution causes destabilization of ColA-P. To test the hypothesis that side chain charge was responsible for ColA-P stability, we replaced the aspartates with asparagines that are the corresponding residues found in colicin N. The result was that most Asp to Asn replacements retained wild type stability (Figure 5); D577N was least stable in the urea unfolding experiment, and D420N was least stable in the DSC 

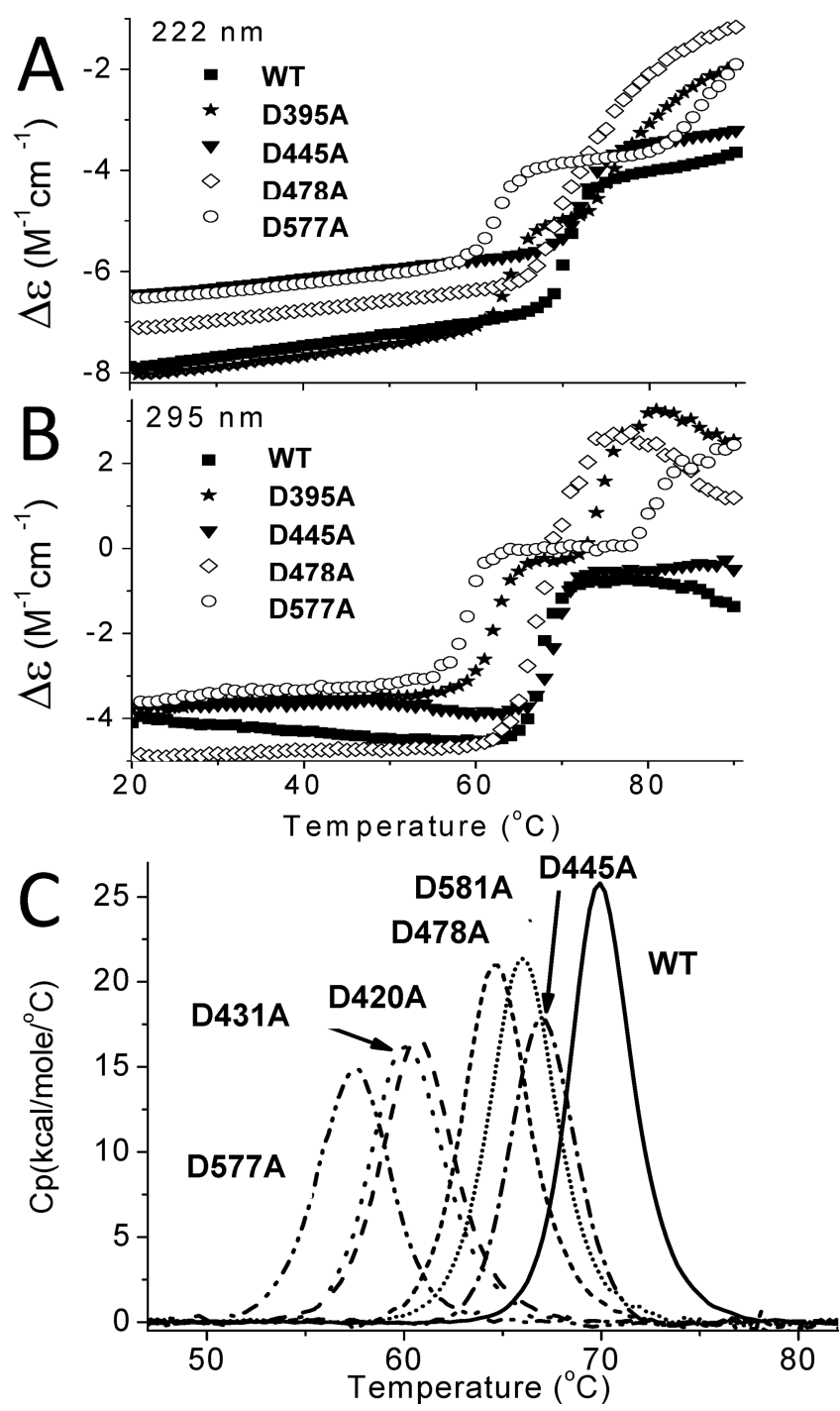

Figure 4. Thermal denaturation data reflect the urea denaturation results. Panels A and B show circular dichroism. The intensity was measured at (A) $222 \mathrm{~nm}$ to measure secondary structure ( $\alpha$ helix) content and (B) $295 \mathrm{~nm}$ to measure the tertiary structure signal provided by buried aromatic residues. (C) DSC thermograms for each mutant at $\mathrm{pH}$ 7.0.

Table 1

$\begin{array}{ccc}\text { mutation } & \begin{array}{c}\text { thermal transition temperature } T_{\mathrm{m}}\left({ }^{\circ} \mathrm{C}\right) \\ \pm \text { error }^{a}\end{array} & \begin{array}{c}\Delta H_{\text {cal }}(\mathrm{kcal} / \mathrm{mol}) \\ \text { error }^{a}\end{array} \\ \text { D420A } & 60.8 \pm 0.02 & 80.8 \pm 1.6 \\ \text { D431A } & 60.2 \pm 0.01 & 79.3 \pm 0.4 \\ \text { D445A } & 67.0 \pm 0.01 & 75.1 \pm 0.6 \\ \text { D478A } & 64.6 \pm 0.02 & 92.5 \pm 0.8 \\ \text { D577A } & 57.5 \pm 0.01 & 71.8 \pm 0.4 \\ \text { D581A } & 66.0 \pm 0.01 & 94.3 \pm 0.7 \\ \text { WT } & 70.0 \pm 0.01 & 107.8 \pm 0.5\end{array}$

${ }^{a}$ Errors represent the quality of the fit of the curve to the data. Errors due to protein concentrations, which will affect $\Delta H_{\text {cal }}$ measured by UV absorption, are generally less than $\pm 5 \%$.

experiment. These data show that hydrogen bond acceptors, and not just negative charges, are needed at these positions for colicin P-domain stability.
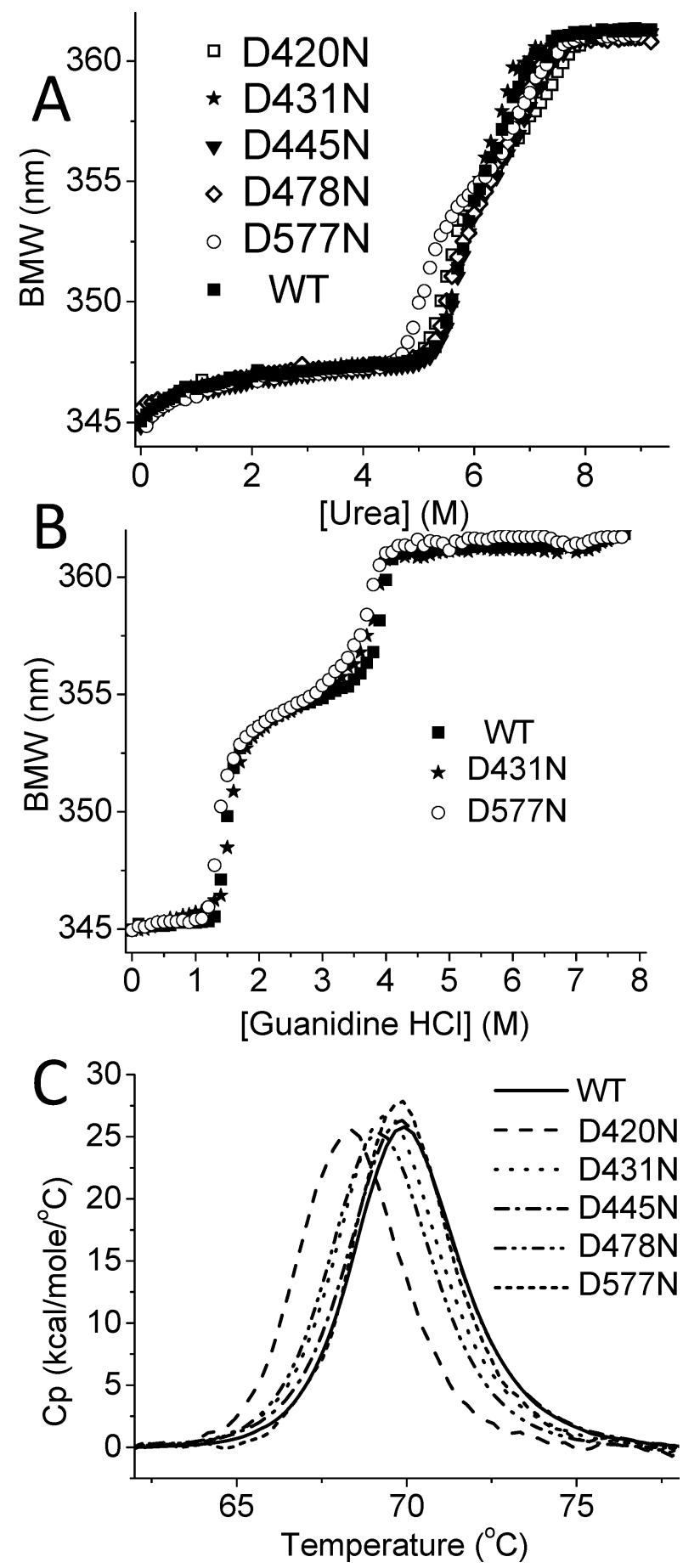

Figure 5. Asp to Asn mutant data. (A) Unfolding of mutants induced by urea and measured by intrinsic tryptophan fluorescence at $\mathrm{pH}$ 7.0. BMW is the barycentric mean wavelength of intrinsic tryptophan fluorescence. (B) $\mathrm{GdnHCl}$ unfolding measured in the same way. (C) DSC thermograms.

Destabilizing Residues Are Mostly Helix N-Capping Residues. A potential explanation for ColA-P $\mathrm{pH}$ sensitivity that would account for the instability of the protonated aspartyl residues $\left(\mathrm{Asp}^{\circ}\right)$ and the stability of asparaginyl mutants involves the role of helix-capping residues. ${ }^{42}$ The ends of $\alpha$ helices present unpaired hydrogen bond donors (peptide amides) at the $\mathrm{N}$-terminus and acceptors (peptide carbonyl oxygens) at the C-terminus. In addition, the orientation of hydrogen bonds along the helix contributes to 
an overall helix macrodipole that may amount to 0.5 of a unit charge with the $\mathrm{N}$-terminus being positive. Thus, residues with side chains that form the required hydrogen bonds or balance the dipole can stabilize the ends of $\alpha$ helices. These are termed either N-Cap or C-Cap residues. ${ }^{43}$ The magnitude of these effects has been measured in both proteins and model peptides. ${ }^{28,44}$ The relative stabilization energies vary slightly, but both studies show that $\mathrm{Asp}^{-}$and Asn are the most stabilizing $\mathrm{N}$-Cap residues while protonated $\mathrm{Asp}^{\circ}$ and $\mathrm{Ala}$ are ineffective, in agreement with our data. The common mechanism for N-Cap stabilization, also supported by the frequencies of particular residues at helix $\mathrm{N}$-termini, is therefore hydrogen bond acceptance rather than electrostatics. $^{42}$

Inspection of the structure of ColA- ${ }^{24}$ for such occurrences showed that D395, D420, D445, D478, and D577 occupy NCap positions at the $\mathrm{N}$-terminal ends of $\alpha$ helices (Figure 1 and Figure S3). The other aspartate residues that are more stable than their alanine replacements are D431, which is near the N-terminus of helix 3, and D581, which is midway along helix 10; thus, their mechanism of stabilization is less clear.

Due to their longer side chains, Glu and Gln lose more degrees of freedom and, in helical peptide models, are less stabilizing N-Cap residues than Asp and Asn. ${ }^{43}$ To further test the N-capping hypothesis, we therefore introduced additional mutations to replace Asp with Glu or Gln. The DSC data (Figure 6) at three sites indicate that these substitutions can

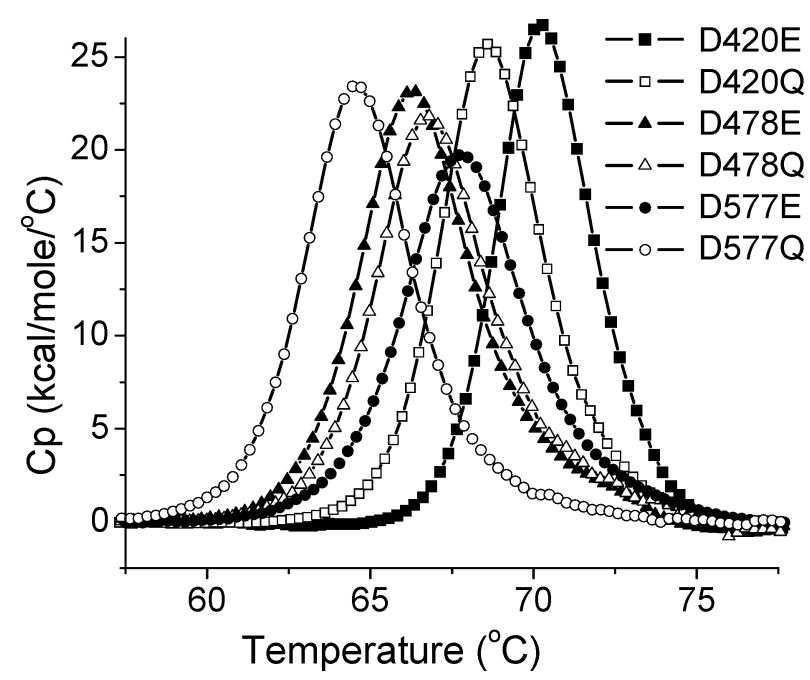

Figure 6. Glutamate and glutamine insertions at three N-Cap sites show intermediate thermal stability. Differential scanning calorimetry data $\left(1{ }^{\circ} \mathrm{C} / \mathrm{min}\right)$ for each of the ColA-P mutants in $50 \mathrm{mM}$ phosphate buffer ( $\mathrm{pH} 7.0$ ). For reference, D420E has wild type stability.

stabilize the protein, with Glu being more stable than Gln. Interestingly, position 420, which was not well stabilized by Asn, shows WT stability when replaced with either Gln or Glu. On the other hand, the same substitutions at positions 478 and 577 are less stable than Asn. Urea denaturation measurements reveal that Glu/Gln insertions are more stabilizing than expected but that the second transition at $\mathrm{pH} 3.0$ is significantly destabilized by Gln or Glu insertions at positions 420 and 478. These are the first mutations to clearly target only the second transition (Figure 7).

HSQC NMR Shows That Ala Mutants Retain Acidic Structure at pH 8.0. To observe the effects of the mutants on the dynamics of the protein backbone, we carried out ${ }^{1} \mathrm{H}-{ }^{15} \mathrm{~N}$ HSQC NMR experiments on ${ }^{15} \mathrm{~N}$-labeled ColA-P WT and mutants D420A, D431A, and D478A. The WT spectrum had been previously assigned by ref 45 at $\mathrm{pH} 4.5$, and our spectrum at $\mathrm{pH} 4.5$ is similar, allowing us to tentatively assign 123 peaks of the previously reported 196 peaks from a total of 206 main chain amide protons in our spectra (Figures S4 and S5). Toward the center of the spectrum where many resonances overlap, reliable assignment was not possible. The few differences between the two spectra may be due to one or more of the following: (i) a hexahistidine tag on the $\mathrm{N}$ terminus of our ColA-P, (ii) three extra amino acids on the Nterminus of the published ColA-P, and (iii) the published protein being dissolved in acetate rather than citrate buffer. The spectra of three mutants were measured at $\mathrm{pH} 4.5$ and compared with that of the WT. In each case, few of the assigned resonances were shifted from the WT positions. These included, as expected, some neighboring residues and a few on distant parts of the protein that did not appear to follow any pattern. The WT spectra at $\mathrm{pH} 4.0$ and 3.5 were not significantly different from those at $\mathrm{pH} 4.5$, but at $\mathrm{pH} 3.0$, the ${ }^{1} \mathrm{H}-{ }^{15} \mathrm{~N}$ HSQC spectra collapsed on the ${ }^{1} \mathrm{H}$ axis to resemble that of a molten globule in agreement with the DSC data (Figure 2D). Urea spectra showed even less ${ }^{1} \mathrm{H}$ dispersion (Figure S6), confirming that the low-pH structure retains some secondary structure. The mutants showed largely similar behavior at $\mathrm{pH} 3.0$, and the lack of assignments prevented useful analysis of this state. The spectra of the mutants at $\mathrm{pH}$ 4.5 resembled that of the WT, but with an increase to $\mathrm{pH} 8.0$, clear differences arose. The WT HSQC spectra showed clear and widespread changes in the ${ }^{1} \mathrm{H}$ dimension due to the $\mathrm{pH}$ change (Figure 8), in agreement with Figure 2A, and D478A was similar (see the Supporting Information). In two mutants (D420A and D431A), the spectra at $\mathrm{pH} 8.0$ were similar to the $\mathrm{pH} 4.5$ data (Figure 8), showing that these two mutants remain in a low-pH state, and the result correlates well with the results of urea denaturation in Figure 2. This also suggests that the shifts in spectra are associated with the first unfolding transition. In the WT at $\mathrm{pH} 4.5$ and the mutants, we observed more resonances than backbone amide protons in the protein, indicating that multiple conformations are present in these destabilized forms (see the Supporting Information).

\section{DISCUSSION}

Colicins $\mathrm{A}$ and $\mathrm{N}$, highly homologous but with very different $\mathrm{pH}$ sensitivities, ${ }^{20}$ provide a tractable system for understanding biologically relevant acid unfolding of proteins. It is wellknown that insertion of the helical colicin pore-forming (P-) domain into membranes requires the formation of an insertion competent state such as a molten globule. ${ }^{16,46}$ In colicin A, this occurs at low $\mathrm{pH}$ in vitro and in vivo; on the other hand, colicin $\mathrm{N}$, like most colicins, does not show acid unfolding, and what forms its membrane insertion competent form is unclear. ${ }^{47}$

When compared to ColN-P, ColA-P possesses seven additional Asp residues, and we showed previously that their replacement with Ala caused destabilization and faster membrane insertion. ${ }^{26}$ Here we examined why colicin A relies upon aspartate residues for its neutral stability and acid instability.

Protein stability measurements using urea denaturation and monitored by tryptophan fluorescence revealed that, unexpectedly, ColA-P unfolds in two stages. The first one leads to an intermediate similar to a molten globule, and it is this 

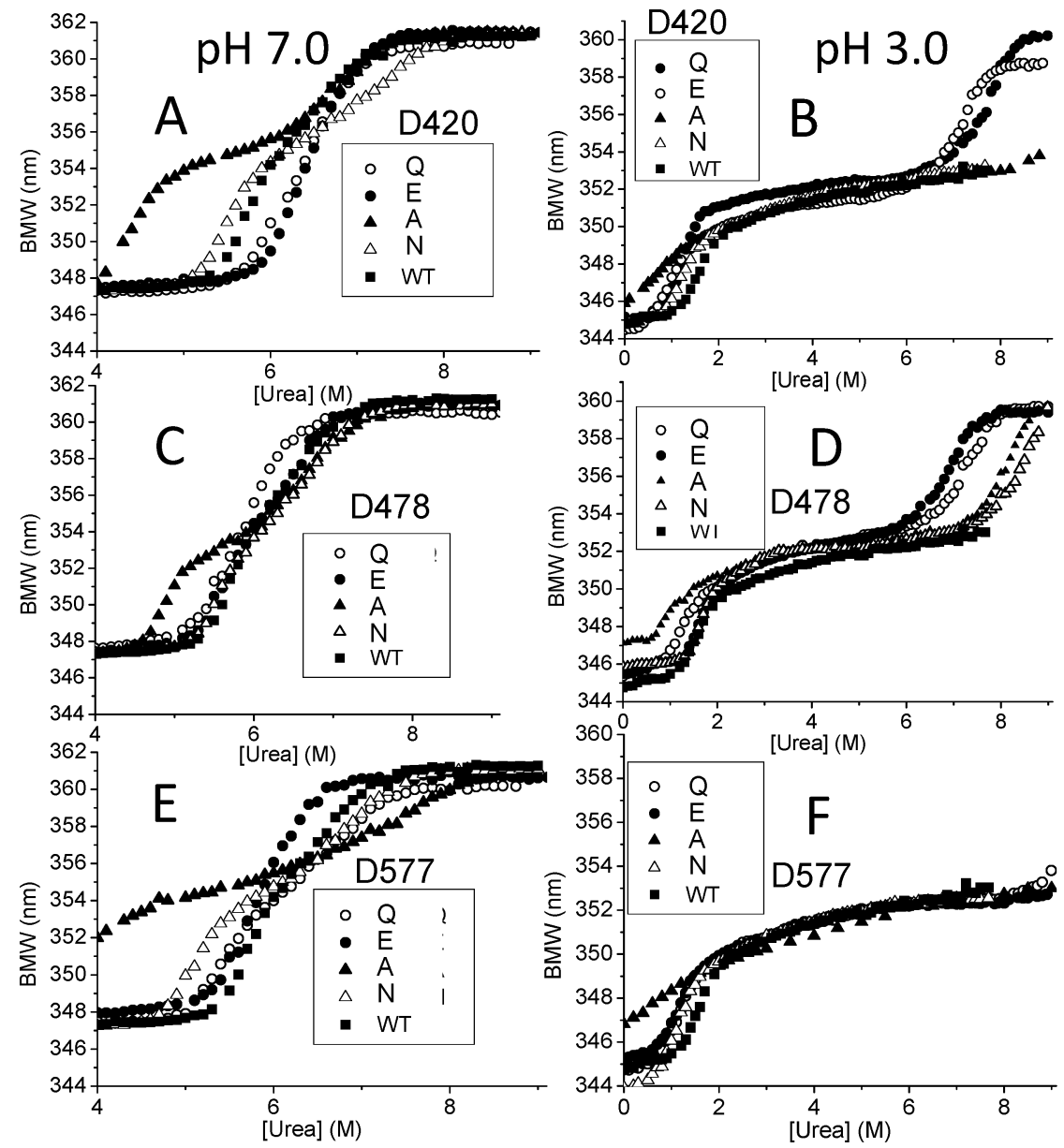

Figure 7. N-Cap glutamate and glutamine insertions are more stabilizing than predicted in urea denaturation experiments. Effects of glutamine and glutamate replacement mutants at three $\mathrm{N}$-Cap positions on urea-induced unfolding at $\mathrm{pH} 7.0$ and 3.0. Unfolding is followed by the change in the barycentric mean wavelength $(\mathrm{BMW})$ of the intrinsic tryptophan fluorescence. Results are also shown for the relevant asparagine and alanine mutations and the WT (see Figures 2-5). Panels A, C, and E show pH 7.0 results for mutations at positions D420, D478, and D577, respectively, and panels B, D, and F show $\mathrm{pH} 3.0$ results for mutations at positions D420, D478, and D577, respectively.

transition that is destabilized by low $\mathrm{pH}$. Surprisingly, the second transition is stabilized by low $\mathrm{pH}$. The first transition is also destabilized by the previously published Asp-to-Ala mutations, ${ }^{26}$ confirming the ability of these mutations to create an unfolded intermediate at neutral $\mathrm{pH}$.

We searched the literature for a general model that would explain the destabilization effects of the alanine substitutions. One explanation relies upon the substantial published evidence that indicates that surface charges can contribute to protein stability, ${ }^{48}$ and a strong indicator of a role for charged surface residues in stability is a change in $\mathrm{p} K_{\mathrm{a}}$ upon folding $\left(\Delta \mathrm{p} K_{\mathrm{a}}\right.$ fold). ${ }^{49}$ This renders protein folding sensitive to $\mathrm{pH}$. These $\Delta \mathrm{p} K_{\mathrm{a}}$ fold values can be determined experimentally, but it has been shown the available prediction algorithms are generally accurate. ${ }^{49}$ Using PROPKA $3.1^{50}$ and the structure of ColA-P (chain A of $1 \mathrm{COL}^{24}$ ), only Asp 577 was predicted to have a large $\Delta \mathrm{p} K_{\mathrm{a}}$ fold with a $\mathrm{p} K_{\mathrm{a}}$ in the folded state of $2.0, \approx 1.6-2.0$ $\mathrm{pH}$ units below that of aspartyl residues in unfolded polypeptides. However, the remaining Asp residues that stabilize ColA-P do not have a large predicted $\Delta \mathrm{p} K_{\mathrm{a}}$ fold. Finally, we examined another study that predicted the surface aspartates in colicin A to be stabilizing, and therefore, their removal and replacement with alanines or protonation could be destabilizing. ${ }^{51}$ This approach, which compares the interactions of the charged residues in folded and unfolded states, accurately models the unfolding of colicin $\mathrm{A}$ at low $\mathrm{pH}$ but does not predict the big difference between colicin A and $\mathrm{N}$. In the absence of an explanation from previous studies, we imitated ColN-P by replacing individual ColA-P aspartyl residues with asparagine. These mutants retained WT stability without a negative charge.

The combined data supported the N-Cap hypothesis for $\alpha$ helix stabilization where polar side chains of N-terminal amino acid residues are able to act as hydrogen bond acceptors from the free amide protons in the final N-terminal turn of a helix. The preferred residue types are Asp, Glu, Asn, and Gln, which we show here provide similar stability at $\mathrm{pH}$ 7.0. At low $\mathrm{pH}$, neutral, $\mathrm{Asp}^{\circ}$ is far less stable as an N-Cap residue than $\mathrm{Asp}^{-28}$ Therefore, the simultaneous protonation of a number of $\mathrm{N}$ Cap aspartyl groups is sufficient to explain the formation of the colicin A acidic molten globule and its in vivo behavior.

Not all of the ColA-P N-Cap structures involve direct hydrogen bonds, and we also do not see the large stability differences between Asn and Gln predicted by results from model peptides. $^{52-54}$ Therefore, importantly, although the results observed in helical model peptides do find parallels in surveys of protein structures, ${ }^{55}$ they are often not exactly reproduced in folded proteins. ${ }^{56,57}$ For example, it was shown for T4 lysozyme mutants that introduced aspartate and asparagine residues at helix $\mathrm{N}$-caps did not need to make 


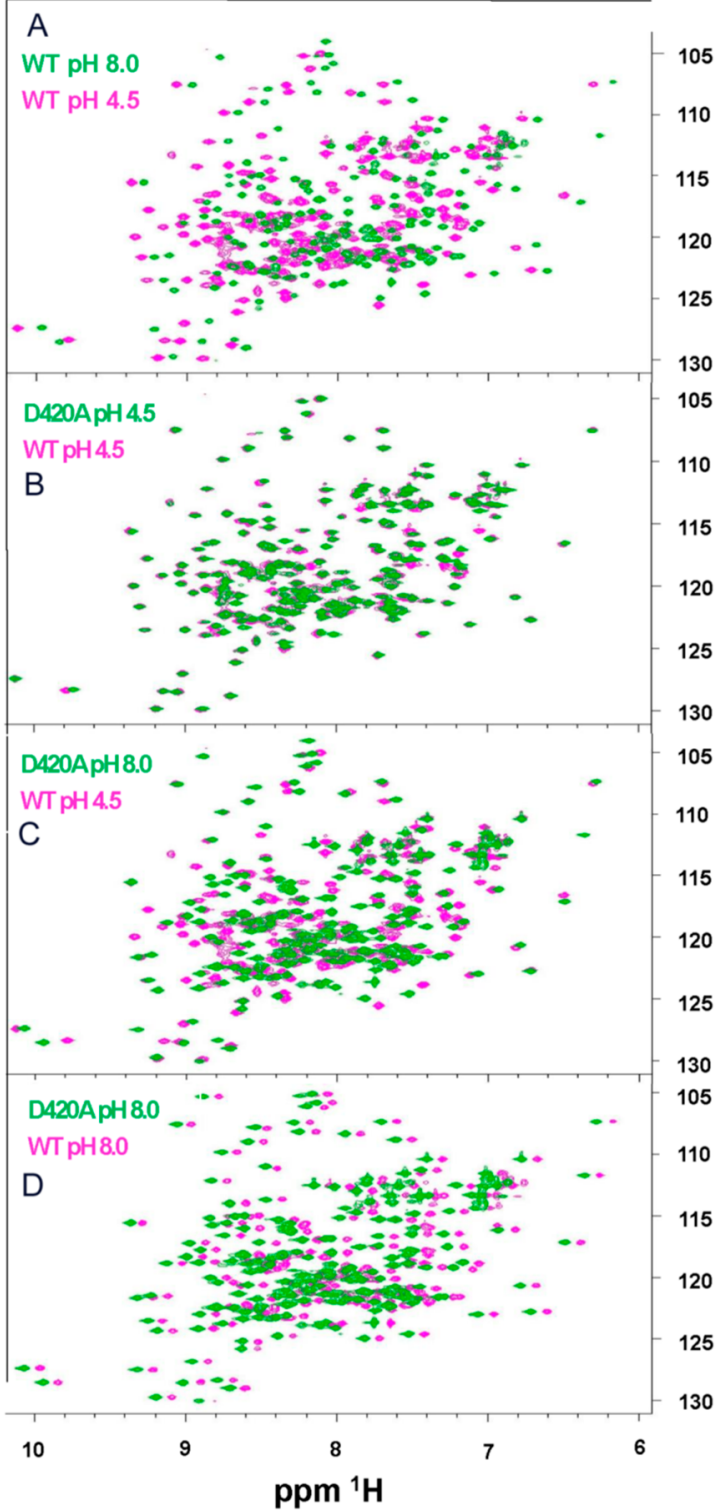

Figure 8. NMR shows that D420A retains its low-pH conformation at $\mathrm{pH}$ 8.0. ${ }^{1} \mathrm{H}-{ }^{15} \mathrm{~N}$ HSQC spectra of ${ }^{15} \mathrm{~N}$-labeled ColA-P. The region of data mainly shows peptide backbone amide $(\mathrm{N}-\mathrm{H})$ resonances. (A) The wild type ColA-P ${ }^{1} \mathrm{H}$ spectrum shows a general shift to a higher field when the $\mathrm{pH}$ is increased to 8.0. (B) WT and D420A spectra at $\mathrm{pH} 4.5$ show similar distributions. (C) The D420A spectrum at $\mathrm{pH}$ 8.0 remains similar to the WT spectrum at $\mathrm{pH}$ 4.5. (D) As expected from the information presented above, at $\mathrm{pH}$ 8.0, WT and D420A spectra show different distributions. The mutant thus retains its $\mathrm{pH}$ 4.5 spectrum at $\mathrm{pH}$ 8.0. The NMRpeak positions are available in the Supporting Information.

specific hydrogen bonds with the free backbone amides to be stabilizing. $^{58}$

Finally, using ${ }^{15} \mathrm{~N}-{ }^{1} \mathrm{H}$ HSQC NMR to detect structural changes of individual amino acid residues, ${ }^{45}$ we observed two clearly different WT spectra at $\mathrm{pH} 8.0$ and 4.5 in which a majority of backbone amide proton resonances were shifted. When we studied two mutants that destabilize the first transition, D420A and D431A, they showed the low-pH HSQC spectrum at $\mathrm{pH} 4.5$ and 8.0. This shows that substitution of a single N-Cap aspartyl group affects the dynamics of the whole pore-forming domain. As a control,
D478A, which is less destabilizing, behaved like the WT. These data also confirm the global influence of the first unfolding transition that corresponds to the creation of the active acidic in vivo form.

So why has ColA-P evolved to need acidic lipids? One possibility is that, following the necessary unfolding associated with outer membrane translocation, ColA-P is maintained in an unfolded state, guiding the pore-forming domain to the correct inner membrane lipid domains and their associated proteins. More recently, the possibility that negatively charged lipids may form concentrated domains in the bacterial inner membrane could explain why even a small mole fraction of acidic lipids could have a sufficiently strong effect on protein side chain protonation. ${ }^{10,59,60}$ However, precise identification of such domains and the negative lipids involved remains challenging. ${ }^{61}$ Current work on lipid distribution in bacterial membranes may shed light on this, and colicin A may prove to be a useful probe of lipid composition. ${ }^{10,31-33,61}$

\section{ASSOCIATED CONTENT}

Supporting Information

The Supporting Information is available free of charge on the ACS Publications website at DOI: 10.1021/acs.biochem.9b00705.

Additional supporting data (XLSX)

Figures S1-S6 and additional references (PDF)

\section{Accession Codes}

The accession ID for the colicin A pore-forming domain is Q47108.

\section{AUTHOR INFORMATION}

\section{Corresponding Author}

*E-mail: jeremy.lakey@ncl.ac.uk.

ORCID $\odot$

Christopher L. Johnson: 0000-0002-7158-4790

Jeremy H. Lakey: 0000-0003-4646-9085

Funding

The authors thank the Welcome Trust for Equipment Grant 064345. C.L.J. and A.S.S. were funded by Welcome Trust Grant 093581. A.S. and A.P.L.B. were funded by BBSRC studentships.

\section{Notes}

The authors declare no competing financial interest.

\section{ACKNOWLEDGMENTS}

The authors thank Daniel Peters and Tharin Blumenschein for help with structural analysis.

\section{ABBREVIATIONS}

ColA-P, colicin A P-domain; ColN-P, colicin N P-domain; $\mathrm{CD}$, circular dichroism; DSC, differential scanning calorimetry.

\section{REFERENCES}

(1) Abrami, L., Liu, S., Cosson, P., Leppla, S. H., and van der Goot, F. G. (2003) Anthrax toxin triggers endocytosis of its receptor via a lipid raft-mediated clathrin-dependent process. J. Cell Biol. 160, 321328

(2) Chenal, A., Prongidi-Fix, L., Perier, A., Aisenbrey, C., Vernier, G., Lambotte, S., Fragneto, G., Bechinger, B., Gillet, D., Forge, V., and Ferrand, M. (2009) Deciphering Membrane Insertion of the Diphtheria Toxin T Domain by Specular Neutron Reflectometry and Solid-State NMR Spectroscopy. J. Mol. Biol. 391, 872-883. 
(3) Rodnin, M. V., Li, J., Gross, M. L., and Ladokhin, A. S. (2016) The $\mathrm{pH}-\mathrm{Dependent}$ Trigger in Diphtheria Toxin T Domain Comes with a Safety Latch. Biophys. J. 111, 1946-1953.

(4) Sandvig, K., and Olsnes, S. (1980) Diphtheria-toxin entry into cells is facilitated by low pH. J. Cell Biol. 87, 828-832.

(5) Bullough, P. A., Hughson, F. M., Skehel, J. J., and Wiley, D. C. (1994) Structure of influenza hemagluttinin at the $\mathrm{pH}$ of membrane fusion. Nature 371, 37-43.

(6) Maeda, T., and Ohnishi, S. (1980) Activation of influenza virus by acidic media cuases hemolysis and fusion of erythrocytes. FEBS Lett. 122, 283-287.

(7) Lam, K. H., Guo, Z. J., Krez, N., Matsui, T., Perry, K., Weisemann, J., Rummel, A., Bowen, M. E., and Jin, R. S. (2018) A viral-fusion-peptide-like molecular switch drives membrane insertion of botulinum neurotoxin A1. Nat. Commun. 9, 5367.

(8) Masuyer, G., Conrad, J., and Stenmark, P. (2017) The structure of the tetanus toxin reveals $\mathrm{pH}$-mediated domain dynamics. EMBO Rep. 18, 1306-1317.

(9) García-Sáez, A. J., Buschhorn, S. B., Keller, H., Anderluh, G., Simons, K., and Schwille, P. (2011) Oligomerization and Pore Formation by Equinatoxin II Inhibit Endocytosis and Lead to Plasma Membrane Reorganization. J. Biol. Chem. 286, 37768-37777.

(10) Renner, L. D., and Weibel, D. B. (2011) Cardiolipin microdomains localize to negatively curved regions of Escherichia coli membranes. Proc. Natl. Acad. Sci. U. S. A. 108, 6264-6269.

(11) Chatterjee, A., Caballero-Franco, C., Bakker, D., Totten, S., and Jardim, A. (2015) Pore-forming Activity of the Escherichia coli Type III Secretion System Protein EspD. J. Biol. Chem. 290, 25579-25594. (12) Cascales, E., Buchanan, S. K., Duche, D., Kleanthous, C., Lloubes, R., Postle, K., Riley, M., Slatin, S., and Cavard, D. (2007) Colicin biology. Microbiol. Mol. Biol. Rev. 71, 158-229.

(13) Kim, Y. C., Tarr, A. W., and Penfold, C. N. (2014) Colicin import into E. coli cells: A model system for insights into the import mechanisms of bacteriocins. Biochim. Biophys. Acta, Mol. Cell Res. 1843, 1717-1731.

(14) Lakey, J. H., and Slatin, S. L. (2001) Pore-forming colicins and their relatives. In Pore-Forming Toxins (Van Der Goot, F. G., Ed.) pp 131-161, Springer Verlag, Heidelberg, Germany.

(15) Anderluh, G., and Lakey, J. H. (2008) Disparate proteins use similar architectures to damage membranes. Trends Biochem. Sci. 33, 482-490.

(16) van der Goot, F. G., González-Mañas, J. M., Lakey, J. H., and Pattus, F. (1991) A 'molten-globule' membrane-insertion intermediate of the pore-forming domain of colicin A. Nature 354, 408-410.

(17) van der Goot, F. G., Didat, N., Pattus, F., Dowhan, W., and Letellier, L. (1993) Role of acidic lipids in the translocation and channel activity of colicins $\mathrm{A}$ and $\mathrm{N}$ in Escherichia coli cells. Eur. J. Biochem. 213, 217-221.

(18) Hilsenbeck, J. L., Park, H., Chen, G., Youn, B., Postle, K., and Kang, C. (2004) Crystal structure of the cytotoxic bacterial protein colicin B at 2.5Å resolution. Mol. Microbiol. 51, 711-720.

(19) Ortega, A., Lambotte, S., and Bechinger, B. (2001) Calorimetric investigations of the structural stability and interactions of colicin $B$ domains in aqueous solution and in the presence of phospholipid bilayers. J. Biol. Chem. 276, 13563-13572.

(20) Evans, L. J. A., Goble, M. L., Hales, K., and Lakey, J. H. (1996) Different sensitivities to acid denaturation within a family of proteins; Implications for acid unfolding and membrane translocation. Biochemistry 35, 13180-13185.

(21) Merrill, A. R., Steer, B. A., Prentice, G. A., Weller, M. J., and Szabo, A. G. (1997) Identification of a chameleon-like pH-sensitive segment within the colicin E1 channel domain that may serve as the $\mathrm{pH}$-activated trigger for membrane bilayer association. Biochemistry $36,6874-6884$.

(22) Musse, A. A., and Merrill, A. R. (2003) The molecular basis for the $\mathrm{pH}$-activation mechanism in the channel-forming bacterial colicin E1. J. Biol. Chem. 278, 24491-24499.

(23) Schendel, S. L., and Cramer, W. A. (1994) On the nature of the unfolded intermediate in the in-vitro transition of the colicin E1 channel domain from the aqueous to the membrane phase. Protein Sci. 3, 2272-2279.

(24) Parker, M. W., Postma, J. P., Pattus, F., Tucker, A. D., and Tsernoglou, D. (1992) Refined structure of the pore-forming domain of colicin A at 2.4 A resolution. J. Mol. Biol. 224, 639-657.

(25) Vetter, I. R., Parker, M. W., Tucker, A. D., Lakey, J. H., Pattus, F., and Tsernoglou, D. (1998) Crystal structure of a colicin N fragment suggests a model for toxicity. Structure 6, 863-874.

(26) Fridd, S. L., and Lakey, J. H. (2002) Surface aspartate residues are essential for the stability of colicin A P-domain: A mechanism for the formation of an acidic molten-globule. Biochemistry 41, 15791586.

(27) Yang, A. S., and Honig, B. (1993) On the Ph-Dependence of Protein Stability. J. Mol. Biol. 231, 459-474.

(28) Doig, A. J., and Baldwin, R. L. (1995) N- and C-capping preferences for all 20 amino acids in alpha helical peptides. Protein Sci. 4, 1325-1336.

(29) Prasad, M., Thomas, J. L., Whittal, R. M., and Bose, H. S. (2012) Mitochondrial 3 beta-Hydroxysteroid Dehydrogenase Enzyme Activity Requires Reversible $\mathrm{pH}$-dependent Conformational Change at the Intermembrane Space. J. Biol. Chem. 287, 9534-9546.

(30) O'Keefe, D. O., Cabiaux, V., Choe, S., Eisenberg, D., and Collier, R. J. (1992) $\mathrm{pH}$ dependent insertion of proteins into membranes- B-chain mutation of diphteria-toxin that inhibits membrane translocation, Glu-349-Lys. Proc. Natl. Acad. Sci. U. S. A. $89,6202-6206$.

(31) Barak, I., Muchova, K., Wilkinson, A. J., O’Toole, P. J., and Pavlendova, N. (2008) Lipid spirals in Bacillus subtilis and their role in cell division. Mol. Microbiol. 68, 1315-1327.

(32) Epand, R. M., and Epand, R. F. (2009) Domains in bacterial membranes and the action of antimicrobial agents. Mol. BioSyst. 5, $580-587$.

(33) Lopez, D., and Kolter, R. (2010) Functional microdomains in bacterial membranes. Genes Dev. 24, 1893-1902.

(34) Soliakov, A., Kelly, I. F., Lakey, J. H., and Watkinson, A. (2012) Anthrax sub-unit vaccine: The structural consequences of binding rPA83 to Alhydrogel(R). Eur. J. Pharm. Biopharm. 80, 25-32.

(35) Chalton, D. A., and Lakey, J. H. (2010) Simple Detection of Protein Soft Structure Changes. Anal. Chem. 82, 3073-3076.

(36) Lakey, J. H., Massotte, D., Heitz, F., Dasseux, J. L., Faucon, J. F., Parker, M. W., and Pattus, F. (1991) Membrane insertion of the poreforming domain of colicin A. A spectroscopic study. Eur. J. Biochem. 196, 599-607.

(37) Johnson, C. L., Solovyova, A. S., Hecht, O., Macdonald, C., Waller, H., Grossmann, J. G., Moore, G. R., and Lakey, J. H. (2017) The Two-State Prehensile Tail of the Antibacterial Toxin Colicin N. Biophys. J. 113, 1673-1684.

(38) Rai, N., Nollmann, M., Spotorno, B., Tassara, G., Byron, O., and Rocco, M. (2005) SOMO (SOlution MOdeler) differences between X-Ray- and NMR-derived bead models suggest a role for side chain flexibility in protein hydrodynamics. Structure 13, 723-734.

(39) The PyMOL Molecular Graphics System, version 1.3r1 (2010) Schrodinger, LLC.

(40) Muga, A., Gonzaléz-Mañas, J. M., Lakey, J. H., Pattus, F., and Surewicz, W. K. (1993) pH-dependent stability and membrane interaction of the pore-forming domain of colicin-A. J. Biol. Chem. $268,1553-1557$.

(41) Sathish, H. A., Cusan, M., Aisenbrey, C., and Bechinger, B. (2002) Guanidine hydrochloride induced equilibrium unfolding studies of colicin B and its channel-forming fragment. Biochemistry $41,5340-5347$.

(42) Aurora, R., and Rosee, G. D. (1998) Helix capping. Protein Sci. 7, 21-38.

(43) Richardson, J. S., and Richardson, D. C. (1988) Amino-acid preferences for specific locations at the ends of alpha-helices. Science $240,1648-1652$

(44) Serrano, L., Sancho, J., Hirshberg, M., and Fersht, A. R. (1992) Alpha-helix stability in proteins. 1. empirical correlations concerning substitution of side-chains at the $\mathrm{N}$ and $\mathrm{C}$-caps and the replacement 
of alanine by glycine or serine at solvent-exposed surfaces. J. Mol. Biol. 227, 544-559.

(45) Ibanez de Opakua, A., Diercks, T., Viguera, A. R., and Blanco, F. J. (2010) NMR assignment and backbone dynamics of the poreforming domain of colicin A. Biomol. NMR Assignments 4, 33-36.

(46) Bullock, J. O., and Cohen, F. S. (1986) Octyl glucoside promotes incorporation of channels into neutral planar phospholipid bilayers. Studies with colicin Ia. Biochim. Biophys. Acta, Biomembr. 856, 101-108.

(47) Wilmsen, H. U., Pugsley, A. P., and Pattus, F. (1990) Colicin N forms voltage- and $\mathrm{pH}$-dependent channels in planar lipid bilayer membranes. Eur. Biophys. J. 18, 149-158.

(48) Strickler, S. S., Gribenko, A. V., Gribenko, A. V., Keiffer, T. R., Tomlinson, J., Reihle, T., Loladze, V. V., and Makhatadze, G. I. (2006) Protein stability and surface electrostatics: A charged relationship. Biochemistry 45, 2761-2766.

(49) Chan, C.-H., Wilbanks, C. C., Makhatadze, G. I., and Wong, K.B. (2012) Electrostatic Contribution of Surface Charge Residues to the Stability of a Thermophilic Protein: Benchmarking Experimental and Predicted pKa Values. PLoS One 7, No. e30296.

(50) Olsson, M. H. M., Sondergaard, C. R., Rostkowski, M., and Jensen, J. H. (2011) PROPKA3: Consistent Treatment of Internal and Surface Residues in Empirical pK(a) Predictions. J. Chem. Theory Comput. 7, 525-537.

(51) Warwicker, J. (1999) Simplified methods for $\mathrm{pK}(\mathrm{a})$ and acid $\mathrm{pH}$-dependent stability estimation in proteins: Removing dielectric and counterion boundaries. Protein Sci. 8, 418-425.

(52) Cochran, D. A. E., and Doig, A. J. (2001) Effect of the N2 residue on the stability of the alpha-helix for all 20 amino acids. Protein Sci. 10, 1305-1311.

(53) Cochran, D. A. E., Penel, S., and Doig, A. J. (2001) Effect of the N1 residue on the stability of the alpha-helix for all 20 amino acids. Protein Sci. 10, 463-470.

(54) Doig, A. J., and Baldwin, R. L. (1995) N- and C-capping preferences for all 20 amino-acids in alpha-helical peptides. Protein Sci. 4, 1325-1336.

(55) Chakrabartty, A., Doig, A. J., and Baldwin, R. L. (1993) Helix capping propensities in peptides parallel those in proteins. Proc. Natl. Acad. Sci. U. S. A. 90, 11332-11336.

(56) Smith, J. S., and Scholtz, J. M. (1998) Energetics of polar sidechain interactions in helical peptides: Salt effects on ion pairs and hydrogen bonds. Biochemistry 37, 33-40.

(57) Huyghues-Despointes, B. M. P., Scholtz, J. M., and Baldwin, R. L. (1993) Effect of a single aspartate on helix stability at different positions in a neutral alanine-based peptide. Protein Sci. 2, 16041611.

(58) Nicholson, H., Anderson, D. E., Daopin, S., and Matthews, B. W. (1991) Analysis of the interaction between charged side-chains and the alpha-helix dipole using designed thermostable mutants of phage t4-lysozyme. Biochemistry 30, 9816-9828.

(59) Kyrychenko, A., Vasquez-Montes, V., Ulmschneider, M. B., and Ladokhin, A. S. (2015) Lipid Headgroups Modulate Membrane Insertion of pHLIP Peptide. Biophys. J. 108, 791-794.

(60) Vargas-Uribe, M., Rodnin, M. V., and Ladokhin, A. S. (2013) Comparison of Membrane Insertion Pathways of the Apoptotic Regulator Bcl-xL and the Diphtheria Toxin Translocation Domain. Biochemistry 52, 7901-7909.

(61) Pogmore, A. R., Seistrup, K. H., and Strahl, H. (2018) The Gram-positive model organism Bacillus subtilis does not form microscopically detectable cardiolipin-specific lipid domains. Microbiology (London, U. K.) 164, 475-482.

(62) Laue, T. M., Shah, T. V., Ridgeway, T. M., and Pelletier, S. L. (1992) Computer-aided interpretation of analytical sedimentation data for proteins. In Analytical Ultracentrifugation in Biochemistry and Polymer Science; Harding, S. E., Rowe, A. J., and Horton, J. C., Eds.; The Royal Society of Chemistry; pp 90-125. 